\title{
Science and medicine down under
}

\author{
Tony Delamothe, Richard Smith
}

Western Australia is famous for its wild flowers, but its doctors are even wilder. Or so Bruce Shepherd, president of the Australian Medical Association (and a Sydneysider), told the opening session of the BMA's overseas meeting in Perth. The BMA arrived in Perth in early November to find not only a vast isolated land of desert and sea but also streets with Scottish names and Father Christmases, reindeer, and gnomes preparing to sweat their way through summer temperatures that will top $40^{\circ} \mathrm{C}$ many times.

\section{Opening address}

Both British and Australian doctors feel themselves under attack, and Australia is soon likely to face changes in its health service as radical as those underway in Britain. Against this backcloth Professor David Penington, vice chancellor of the University of Melbourne, chose for the title of his opening address "The future of the profession-the tension between autonomy and regulation by government." One message which went down well with the Australian doctors present was that it was vital that private practice continued to exist in Australia for those who chose to spend their disposable income on care that might not be available to all. More broadly, he argued that doctors had to lead the public debate on health care rather than simply react to the plans of others, which were so often mistaken or wrong.

\section{What causes obesity?}

Obesity is a serious problem in both Australia and Britain, and Dr John Munro, a physician from Edinburgh, said that, although it may have a genetic component, it is most usefully thought of as arising from either reduced energy expenditure or increased intake. When patients underestimate their food intake they are usually not lying but deceiving themselves. Dietary histories may miss much: Dr Munro asks about eating between snacks, bingeing, fluid intake, and evening eating as well as about meals and snacks. Eating for pleasure-gluttony-rarely causes obesity; eating for comfort is much more likely to, though Dr Munro is becoming aware that many people, particularly those who were abused as children, eat for protection.

Dr Munro madea plea for setting realistic objectives. For too long failure to lose weight had been equated with failure of treatment: preventing further weight gain might be a more realistic goal. If weight loss was the goal then permanent changes in eating were required: episodic strict dieting is so often followed by rapid weight gain. Aiming for an energy deficit of $4 \cdot 2 \mathrm{MJ}(1000 \mathrm{kcal})$ a day would lead to weight loss of $0.5-1 \mathrm{~kg}$ a week or $25-50 \mathrm{~kg}$ a year.

Understanding why a particular patient wants to lose weight is important according to Dr Munro. For example, trying to save a faltering marriage by losing weight is unlikely to be successful. In treating obese patients empathy is as important as skill: medical students and nurses may achieve better results than "obesologists." $\mathrm{He}$ agreed with a questioner that obesity clinics may be as much part of the problem as part of the solution, contributing to "fattism," whereby a whole class of people is stigmatised.

\section{Perth: home of helicobacter}

One of Perth's claims to medical fame is that it is the home of the idea that Helicobacter pylori may be the cause of gastritis, peptic ulcer, and other diseases of the upper gastrointestinal tract. In 1982 Barry Marshall and Robin Warren noticed the association with gastritis, and Dr K J Christiansen from Perth, who addressed the meeting, was one of the microbiologists who first grew the organism. She said they had the long Western Australia Easter weekend to thank for growing the fastidious organism-because a plate had been left much longer than planned.

Gastroenterologists are now divided into those who think that helicobacter is of central importance in upper gastrointestinal disease and those who don't. Dr Christiansen unsurprisingly presented the case for the believers: the organism is found in the gastric mucosa of over three quarters of those with gastritis (and in almost all if enough biopsy specimens are taken) and is rare in those with normal mucosa. The organism adheres to the diseased mucosa and has produced gastritis in baby pigs and germ free mice. Finally, Koch's postulates have been fulfilled in the case of gastritis because Barry Marshall swallowed a culture of helicobacter and gave himself gastritis, which then disappeared when the organism was eradicated using antibiotics.

The case for helicobacter causing duodenal ulcer is not so strong because nobody has given himself or herself an ulcer through ingesting the organism, but

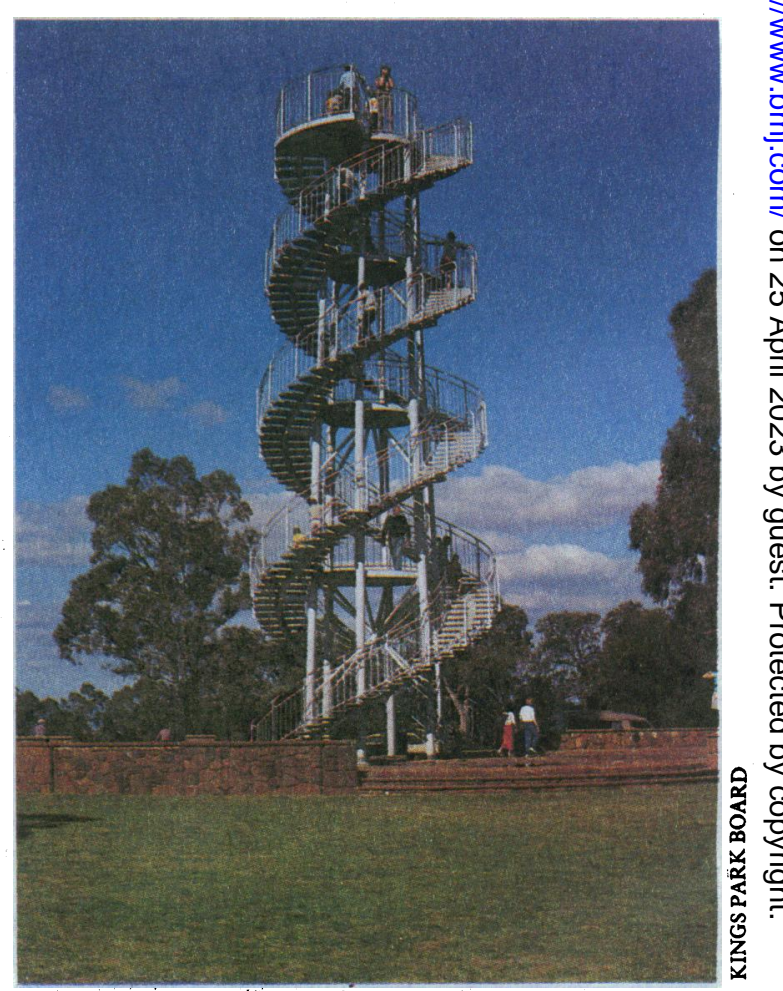

“Double helix" observation tower in Kings Park, Perth 


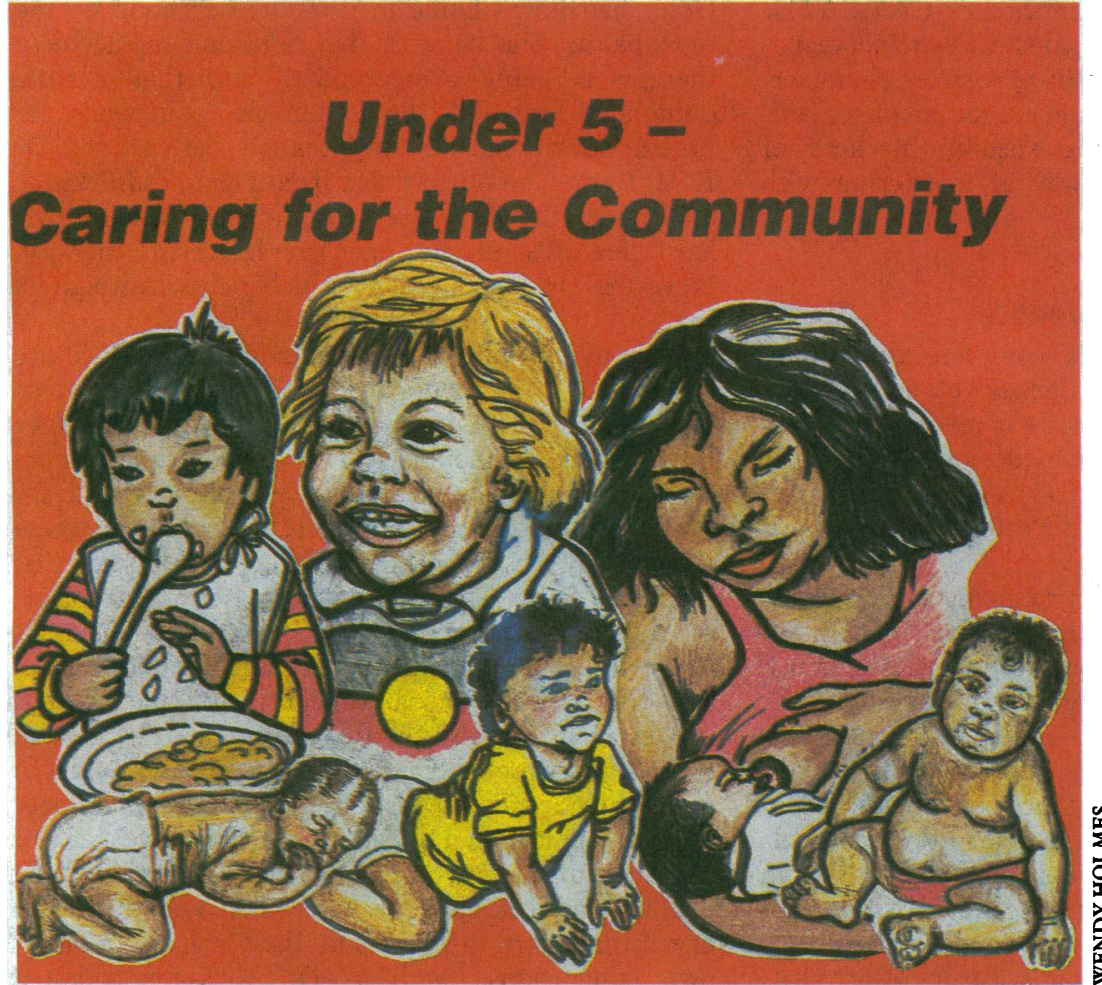

Aboriginal student health workers developed this prent held booklet for children's health records the association between presence of the organism and ulceration is strong. Furthermore, helicobacter is associated with the increased gastrin concentrations that are linked with ulceration. Possibly, said Dr Christiansen, helicobacter blocks the acid feedback that usually reduces acid production or increases gastrin production through inflammation.

Studies of eradicating helicobacter to treat gastritis or duodenal ulcer are mostly, Dr Christiansen conceded, of poor quality. "We are still waiting for the definitive study." But the studies that have been done suggest that combinations of amoxycillin, metronidazole, and bismuth will eradicate the organism and hasten healing of the gastritis or ulcer, and those who remain free of the organism tend not to relapse. But compliance with treatment is a problem because often all three drugs must be used, and the organism also tends quickly to become resistant to metronidazole.

\section{The health of Aboriginal people}

The poor health of Aboriginal people is a hot political issue, and every word spoken by Dr Michael Gracey from the health department of Western Australia was recorded by Australian radio. But Western Australia is proud that it was the first state in which doctors of Aboriginal origin graduated and has better statistics on Aboriginal health than any other.

At the time of the first European settlement (1788) Australian Aborigines were the largest and most successful group of hunter-gatherers in the world. Their nomadic way of life protected them against many epidemic diseases, and they were probably healthier than the first English and Irish settlers. When their isolation was shattered measles, influenza, whooping cough, diphtheria, sexually transmitted diseases, and especially smallpox swept through the Aboriginal population. By the 1930s it was being predicted that the (mainland) Aborigines would die out naturally (unlike the Tasmanian Aborigines, who had been massacred). All that was left for non-Aboriginal Australians was "to smooth the dying pillow."

Reports of the impending extinction turned out to be exaggerated. Although Aborigines may be in a sad state, Dr Gracey said, infant mortality had fallen by about two thirds between 1972 and 1988, and the rates of hospital admission of children for diarrhoeal diseases had fallen by $90 \%$ in the 1970 s. Tuberculosis and leprosy were becoming less common. Dr Gracey reminded his predominantly British audience that some ethnic minorities in the United Kingdom had rates of infant and perinatal mortality twice those of the rest of the population-similar to the differences existing between Aboriginal and non-Aboriginal West Australians.

Overall mortality is two to three times higher among Aborigines; Aboriginal men live 15.4 years less and Aboriginal women live 14 years less than nonAboriginal West Australians. Most of the premature mortality occurs between the ages of 30 and 60 . Comparing hospital admission rates with causes of deaths suggests an underuse of health care resources, particularly for circulatory disorders - the main cause of death for both men and women. The second most common cause of death among Aboriginal men is injury and poisoning, and, although these have multiple causes, many relate to risk taking: alcoholism, alcohol related violence, suicide, homicide, and road accidents.

Intervention requires an understanding of the relation between socioeconomic conditions, housing, hygiene, and education, according to Dr Gracey. Western Australia was currently implementing the national Aboriginal health strategy, which had been drawn up in consultation with the Aborigines.

Many of the points mentioned by Dr Gracey recurred in Dr Sandy Macara's talk on how to reach the underprivileged in society. The greatest problem in health care delivery today was getting it to those in greatest need. The evidence for a relation between social inequalities and ill health was now irrefutable, said Dr Macara. But evidence has also been accumulating that health care systems as they currently operate increase inequality-summed up in Julian Tudor Hart's "inverse care law." The articulate middle class benefits disproportionately from preventive health programmes such as immunisation. Research has shown that poor pregnant women have less chance of receiving specialist care during pregnancy and are more likely to be looked after by junior staff and midwives. Dr Macara counselled against victimising those who chose less healthy options-focusing on personal characteristics obscures the effects of structural inequalities on health.

\section{Mechanisms of autoimmune disease}

Introducing his paper on the mechanisms of autoimmune diseases and potential for new treatment, Professor Keith Peters, regius professor of physic in Cambridge, paid tribute to the work of Australian nobel laureate Sir MacFarlane Burnett for his work on how the body differentiates self from non-self. He reminded his audience that autoimmune disease was the third most important source of illness in the developed world (after cardiovascular disease and cancer). For example, diabetic retinopathy was the main cause of blindness, and diabetic renal disease the main cause of end stage renal failure.

Professor Peters explained that antigens are processed by antigen presenting cells and interact with $T$ lymphocytes, resulting in the production of antibodies. Better understanding of how tolerance to antigens may be induced in $T$ cells leads to the possibility of "reprogramming" the immune system (particularly relevant in cases of autoimmune disease) Isolating $\mathrm{T}$ cells, either by depleting or blocking them, turns them off. Professor Peters and his colleagues in Cambridge have already achieved notable success in treating a patient with longstanding autoimmune 
disease by using lymphotoxic antibodies (CAMPATH$1 \mathrm{H})$ and antibodies directed against CD4 helper cells.

Researchers from Harvard have recently characterised the peptide presenting site on the histocompatibility molecule; synthesising specific blockers of this site might be another way of interfering with autoimmune reactions.

\section{Cancer: from the molecule to politics}

No medical conference is complete these days without some mention of oncogenes yet, as Professor Ken Bagshawe, emeritus professor of medical oncology from London, explained, the explosion of molecular and cell biology has not yet produced much improvement in cancer treatment. But Professor Bagshawe is confident that it will come.

Firstly, the new biology is producing more specific methods of testing potential carcinogens that do not need to use animals. Secondly, those at particular risk of some cancers - including, breast and ovarian cancer - can be identified. Thirdly, similar techniques give information on prognosis in patients with cancer. Fourthly, the growth factors that have emerged from the new biology are already being used in clinical trials to overcome the myelosuppression that results from chemotherapy. Fifthly, there is the possibility of anticancer vaccines, and a vaccine against hepatitis $B$ is already in use and vaccines against Epstein-Barr virus are under trial. Sixthly, earlier diagnosis may be possible. Finally, the better understanding of carcinogenesis opens up many strategies for treatment, including using agents acting against growth factors, gene replacement for the gene loss seen in many cancers, and blocks to the expression of oncogenes. One way that this may be done is to use antisense oligonucleotides, lengths of DNA that are engineered to be inserted as a third strand into the double helix of a particular gene.

But while the new biologists work on the expected bonanza doctors must work on present problems, and Dr Michael Byrne, a medical oncologist from Perth, said that the first way to tackle the problem is primary prevention. West Australia has an outstanding record in combating smoking. Dr Byrne discussed the possibility that tamoxifen might be used for primary prevention of breast cancer and said that when it comes to screening for cancer the case has been proved only for cancers of breast and the cervix.

Dr Byrne's main message was that chemotherapy is underused-both as adjuvant treatment and in palliation. He believes the case has been made that adjuvant therapy will reduce deaths from breast, colon, and rectal cancers at a particular stage by about a quarter to a third. Chemotherapy is probably not used more because of fears about its toxicity-yet Dr Byrne and others from Australia and New Zealand have shown that chemotherapy actually improves the quality of life in patients with advanced cancer. Furthermore, continuous treatment produces greater improvements than intermittent treatment.

\section{Reproductive medicine}

Hormone replacement therapy was in the news in Australia when the BMA was there because Germaine
Greer had flown home to promote her book on the menopause. She believes that hormone replacement therapy is being overpromoted and that a male dominated medical profession is conspiring to pressurise women to stay sexually attractive. Dr K McKenna, an obstetrician from Perth, didn't quite see things that way, but he did acknowledge the agist features of hormone replacement therapy. Nevertheless, he believes that its benefits outweigh its risks.

Nobody disputes that the therapy will reduce the symptoms of the menopause, and Dr McKenna also believes that the evidence is solid that it will reduce bone loss and the incidence of femoral fractures and cut the risk of death from heart disease by about a third. Dr McKenna did accept, however, that some of these results may arise from patient and doctor selection thus $46 \%$ of British patients taking hormone replacement therapy are from social classes I and II. The risks of treatment do not include thromboembolic disease, and risk of endometrial cancer is not increased if progestagens are used with oestrogens. The risk of breast cancer probably is increased by $50-70 \%$ and that of gall bladder disease also, but hormone replacement therapy should lead to about a third fewer deaths overall. But many women may think that a lingering death from breast cancer is worse than a possibly swift one from heart disease, and they will reach their own conclusions. And, as Dr McKenna pointed out, further side effects of the therapy may yet be discovered: the table shows how many of the side effects of oral contraceptives were not apparent when they were first introduced.

Side effects of oral contraception mentioned in the prescribing manual given to American doctors in 1961, 1970, and 1985

\begin{tabular}{lccc}
\hline Condition & 1961 & 1970 & 1985 \\
\hline Thromboembolic disease & - & + & + \\
Cerebrovascular disease & - & + & + \\
Cardiovascular disease & - & - & + \\
Undiagnosed genital bleed & - & + & + \\
Breast cancer & - & + & + \\
Liver tumours & - & - & + \\
Impaired liver function & - & + & -
\end{tabular}

Professor Robert Winston, professor of obstetrics from London, looked at the other end of reproductive life and described how his group at Hammersmith Hospital have had six babies born after preimplantation diagnosis: a cell is removed from the embryo fertilised in vitro, the genes examined using gene amplification, and then the embryo inserted into the mother if there is no defect. So far Professor Winston's group has worked with families with serious $\mathrm{X}$ linked conditions, but now it is extending the programme to families with $N$ single gene disorders. Professor Winston was modest $\rightarrow$ about how much might be achieved in the short term with these techniques, and he ended his talk with a Brueghel print showing how an alchemist had led his family to the poor house through his slavish devotion to modern technology.

The picture provided a suitable conclusion for the

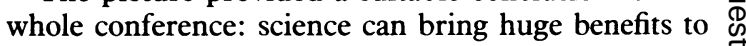
medicine but doctors should not allow themselves to become obsessed with technology at the expense of the basic skills of healing. 